\title{
Comparative evaluation of the efficacy of three methods of delivering calcium hydroxide into the root canal
}

\section{Ocena porównawcza skuteczności trzech metod wprowadzania wodorotlenku wapnia do kanału korzeniowego}

\author{
Roohollah Sharifi ${ }^{1, A, C-F}$, Ehsan Bahrampour ${ }^{2, A-C}$, Pourya Janfroozzade ${ }^{3, A, B}$, Mohsen Safaei ${ }^{4, B-F}$, Hamid Reza Mozaffari ${ }^{5, A, D-F}$, \\ Elham Soltanimehr ${ }^{6, C-F}$, Hedaiat Moradpoor ${ }^{7, A, E, F}$, Mohammad Moslem Imani ${ }^{8, C-F}$ \\ 1 Department of Endodontics, School of Dentistry, Kermanshah University of Medical Sciences, Iran \\ ${ }^{2}$ Department of Oral and Maxillofacial Radiology, School of Dentistry, Kermanshah University of Medical Sciences, Iran \\ ${ }^{3}$ Student Research Committee, School of Dentistry, Kermanshah University of Medical Sciences, Iran \\ ${ }^{4}$ Oral and Dental Sciences Research Laboratory, School of Dentistry, Kermanshah University of Medical Sciences, Iran \\ ${ }^{5}$ Department of Oral and Maxillofacial Medicine, School of Dentistry, Kermanshah University of Medical Sciences, Iran \\ ${ }^{6}$ Department of Pediatric Dentistry, School of Dentistry, Kermanshah University of Medical Sciences, Iran \\ ${ }^{7}$ Department of Prosthodontics, School of Dentistry, Kermanshah University of Medical Sciences, Iran \\ ${ }^{8}$ Department of Orthodontics, School of Dentistry, Kermanshah University of Medical Sciences, Iran \\ A - research concept and design; $B$ - collection and/or assembly of data; $C$ - data analysis and interpretation; \\ $D$ - writing the article; $E$ - critical revision of the article; $F$ - final approval of the article
}

Address for correspondence

Ehsan Bahrampour

E-mail: e.bahrampour@gmail.com

Funding sources

None declared

Conflict of interest

None declared

Received on December 10, 2018

Reviewed on December 13, 2018

Accepted on February 5, 2019

Published online on June 28, 2019

Cite as

Sharifi R, Bahrampour E, Janfroozzade $P$, et al. Comparative evaluation of the efficacy of three methods of delivering calcium hydroxide into the root canal. Dent Med Probl. 2019;56(2):155-159. doi:10.17219/dmp/103732

DOI

10.17219/dmp/103732

Copyright

○ 2019 by Wroclaw Medical University

This is an article distributed under the terms of the

Creative Commons Attribution Non-Commercial License

(http://creativecommons.org/licenses/by-nc-nd/4.0/)

\section{Abstract}

Background. Calcium hydroxide, due to its favorable properties, such as an antimicrobial effect as well as its ability to dissolve necrotic tissues, inhibit tooth resorption and stimulate the formation of a hard tissue barrier, is widely used in root canal treatment.

Objectives. The objective of this study was to compare the efficacy of 3 methods of delivery of calcium hydroxide into the canals.

Material and methods. This in vitro experimental study was performed on acrylic resin blocks with simulated curved canals (curvature of $24^{\circ}$ and $44^{\circ}$ ). Calcium hydroxide was delivered into the canals with 3 different instruments : a hand file, a Lentulo and a rotary file. The data was analyzed using the three-way analysis of variance (ANOVA) and Tukey's test.

Results. The density of calcium hydroxide was significantly different among the 3 groups $(p<0.001)$. The manual delivery technique resulted in the lowest and using a rotary file in the highest density of calcium hydroxide $(p<0.001)$. The mean density of calcium hydroxide was significantly higher in the canals with curvature of $24^{\circ}$, irrespective of the delivery method $(p<0.001)$. The lowest mean density of calcium hydroxide was noted at $1 \mathrm{~mm}$ and $3 \mathrm{~mm}$ from the apex, whereas the highest mean density was noted at $11 \mathrm{~mm}$ from the apex, irrespective of delivery method $(p<0.001)$.

Conclusions. A rotary file seems to be the most efficient instrument for delivering calcium hydroxide into the canals, especially into the apical region of canals with greater curvature.

Key words: calcium hydroxide, hand file, rotary file

Słowa kluczowe: wodotlenek wapnia, pilnik ręczny, pilnik obrotowy 


\section{Introduction}

During endodontic treatment, the infected tissue is often removed using canal irrigation with disinfecting solutions and biomechanical cleaning. After the infected and necrotic tissue has been eliminated, the root canal should be disinfected, instrumented and shaped. ${ }^{1}$ Despite efforts to completely clean and disinfect the root canal system, some microorganisms may still remain lodged in the dentinal tubules. If intracanal medicaments are not used between treatment sessions, the residual microorganisms may proliferate and soon reach their baseline count. ${ }^{2}$

Calcium hydroxide is extensively used as an intracanal medicament. It has many of the properties of an ideal medicament, such as the ability to physically seal the canal and prevent canal reinfection by inhibiting the proliferation of microorganisms. ${ }^{3}$

It also has optimal biological properties such as the ability to dissolve necrotic tissues, inhibit tooth resorption and stimulate the formation of a hard tissue barrier. ${ }^{3}$ It has an analgesic effect and can control inflammation. It shows antimicrobial activity against the majority of endodontic pathogens, as it changes the bacterial cell wall and destructs the molecular structure of endotoxins. ${ }^{4}$ The antimicrobial activity of calcium hydroxide is attributed to its high $\mathrm{pH}$ (12.5). Thus, the efficacy of calcium hydroxide depends on its dissolution and release of hydroxyl ions $\left(\mathrm{OH}^{-}\right)$, which can penetrate into the surrounding tissues. ${ }^{5}$

Calcium hydroxide should be applied in sufficient amounts into the root canal in order to be able to provide adequate concentration of calcium and hydroxyl ions to exert their biological effects. ${ }^{6}$ Calcium hydroxide kills the microorganisms by direct contact. Thus, in order to achieve maximum biological effects, calcium hydroxide should be applied and spread uniformly and with the highest density along the canal working length.,8

Uniform and high-density (condensed) filling of the root canals with calcium hydroxide to the working length depends on the technique of delivery of calcium hydroxide into the canal. Calcium hydroxide can be delivered into the canal with different instruments (e.g., a syringe, a Lentulo, hand files, rotary files, spreaders, and pluggers). To date, few studies have assessed the effect the technique of delivering calcium hydroxide into the root canal system has on its density. ${ }^{9-11}$ Thus, this study aimed to compare the density of calcium hydroxide in simulated root canals in resin blocks following its delivery with a hand file, a Lentulo and a rotary file.

\section{Material and methods}

This in vitro experimental study was performed on simulated root canals with curvature of $24^{\circ}$ and $44^{\circ}$ in resin blocks. The sample size was calculated to be 10 samples in each group according to a study by Simcock and Hicks. ${ }^{7}$
To further increase the accuracy of results, 15 samples were evaluated in each group. A total of 45 canals with curvature of $24^{\circ}$ and 45 canals with curvature of $44^{\circ}$ were evaluated.

Acrylic resin blocks with simulated root canals were used. The size of root canals was 30 and they had curvature of $24^{\circ}$ and $44^{\circ}$. The acrylic blocks were masked by a cover in order for the operating clinician to be blinded to the canal content.

A K-file size 10 (Mani Inc., Tochigi, Japan) exceeded the working length by $1 \mathrm{~mm}$ to ensure absence of canal obstruction. The canal lengths were equal $(13 \mathrm{~mm})$. The acrylic blocks underwent digital radiography perpendicular to the surface of the canal curvature, whereas the $\mathrm{X}$-ray tube was within a distance of $10 \mathrm{~cm}$ from the block and at an angle of $90^{\circ}$ relative to the sensor.

Calcium hydroxide paste (Golchai Co., Tehran, Iran) was prepared with distilled water at $44 \mathrm{wt} \%$ One single clinician applied calcium hydroxide into the canals in all 3 groups. He was blinded to the objectives of the study. The 3 groups were as follows:

- the hand file group - the canals were filled with calcium hydroxide paste using a hand K-file size 25 (Mani Inc.) to the working length counterclockwise;

- the Lentulo group - the canals were filled with calcium hydroxide using a Lentulo size 25 (Dentsply Maillefer US, Tulsa, USA) up to 1-2 $\mathrm{mm}$ to the working length with an air motor handpiece (NSK Ltd., Tokyo, Japan) at a speed of $500 \mathrm{rpm}$;

- the rotary file group - the canals were filled with calcium hydroxide using an Mtwo $^{\circledR}$ rotary file size 25 (VDW, Munich, Germany) to the working length with a limited-torque electric motor (Endo E Class; Saeyang Microtech Co. Ltd., Daegu, Korea) counterclockwise at a constant $150 \mathrm{rpm}$.

The extrusion of calcium hydroxide from the canal orifice in the acrylic block indicated that the canal was filled. ${ }^{7}$ After calcium hydroxide had been applied into the canals in each group, excess paste was removed from the canal orifice and the orifice was sealed using the intermediate restorative material (IRM) (Dentsply Caulk, York, USA).

Digital radiographs were obtained for each canal perpendicular to the canal curvature before and after root canal filling with calcium hydroxide under the same exposure settings $(70 \mathrm{kV}, 6 \mathrm{~mA}, 0.20 \mathrm{~s})$. The $\mathrm{X}$-ray tube was within a distance of $10 \mathrm{~cm}$ from the sample and at angle of $90^{\circ}$ relative to the sensor. The sensor was held with a cardboard positioning device and each tooth was taped to the sensor to ensure that all radiographs were taken from the same position. Fifteen radiographs were obtained for the canals with curvature of $44^{\circ}$ in each group (a total of 45 radiographs) and 15 radiographs were obtained for the canals with curvature of $24^{\circ}$ in each group (a total of 45 radiographs).

An expert oral and maxillofacial radiologist analyzed the radiographs using the DIGORA ${ }^{\mathrm{TM}}$ software (Soredex, Helsinki, Finland) twice with a 1-week interval. To assess the intra-examiner reliability, the intraclass correlation coefficient (ICC) was calculated (0.93). 
The radiologist was not aware of the group allocation of the samples. To analyze the radiographs, first the calibration was performed using a 6-step aluminum step wedge, and then horizontal lines at a distance of $1 \mathrm{~mm}, 3 \mathrm{~mm}, 7 \mathrm{~mm}$, and $11 \mathrm{~mm}$ from the apex were drawn on each radiograph using the ruler of the software. Using the densitometry feature, a perpendicular line was drawn at the center of the canal and density was recorded at the intersection points of this line and the previously drawn horizontal lines. The density values are between 0 and 256 shades of grey.

The data was analyzed with the PASW Statistics for Windows, v. 18.0 (SPSS Inc., Chicago, USA) using descriptive and inferential statistics. The normal distribution of data was evaluated using the Kolmogorov-Smirnov test. Since the density data was normally distributed $(p>0.05)$, the comparisons were made using the three-way analysis of variance (ANOVA). Tukey's post-hoc test was applied for pairwise comparisons. A value of $p<0.05$ was considered statistically significant.

\section{Results}

Table 1 shows the mean density of calcium hydroxide at different levels from the apex according to the canal curvature in the 3 groups. According to the three-way ANOVA, there was a significant difference in the mean density of calcium hydroxide among the 3 groups $(p<0.001)$. The manual technique group showed the lowest and the rotary file group the highest mean density of calcium hydroxide in the canals (Table 2).

The three-way ANOVA also showed a significant difference in density of calcium hydroxide between the canals with curvature of $24^{\circ}$ and $44^{\circ}(p<0.001)$. The mean density of calcium hydroxide was higher in the canals with curvature of $24^{\circ}$ than in the case of the canals with curvature of $44^{\circ}$ (Table 3). A significant difference was revealed in the density of calcium hydroxide at different distances from the apex $(p<0.001)$ - the lowest mean density was noted at $1 \mathrm{~mm}$ and $3 \mathrm{~mm}$ from the apex, whereas the highest mean was noted at $11 \mathrm{~mm}$ from the apex (Table 4).

Table 1. Mean density of calcium hydroxide at different distances from the apex according to the canal curvature in the 3 groups

\begin{tabular}{|c|c|c|c|c|}
\hline Distance & $\begin{array}{c}\text { Canal } \\
\text { curvature }\end{array}$ & Hand file & Lentulo & Rotary file \\
\hline \multirow{2}{*}{$1 \mathrm{~mm}$} & $24^{\circ}$ & $63.27 \pm 10.54$ & $74.53 \pm 32.64$ & $101.80 \pm 21.57$ \\
\hline & $44^{\circ}$ & $43.67 \pm 20.60$ & $48.87 \pm 21.99$ & $92.80 \pm 23.83$ \\
\hline \multirow{2}{*}{$3 \mathrm{~mm}$} & $24^{\circ}$ & $65.13 \pm 7.45$ & $76.33 \pm 32.57$ & $100.27 \pm 19.62$ \\
\hline & $44^{\circ}$ & $41.60 \pm 12.00$ & $50.53 \pm 23.16$ & $95.73 \pm 22.86$ \\
\hline \multirow{2}{*}{$7 \mathrm{~mm}$} & $24^{\circ}$ & $70.73 \pm 10.50$ & $81.93 \pm 27.40$ & $101.93 \pm 17.54$ \\
\hline & $44^{\circ}$ & $56.40 \pm 14.24$ & $57.73 \pm 22.04$ & $100.80 \pm 23.79$ \\
\hline \multirow{2}{*}{$11 \mathrm{~mm}$} & $24^{\circ}$ & $71.13 \pm 14.98$ & $93.33 \pm 28.59$ & $103.40 \pm 18.23$ \\
\hline & $44^{\circ}$ & $73.40 \pm 15.69$ & $67.47 \pm 23.07$ & $101.40 \pm 28.10$ \\
\hline
\end{tabular}

Data presented as mean \pm standard deviation (SD).
Table 2. Mean density of calcium hydroxide in the canals in the 3 methods

\begin{tabular}{|l|c|c|c|c|}
\hline \multicolumn{1}{|c|}{ Method } & Mean & SD & Minimum & Maximum \\
\hline Hand file & $60.67^{\mathrm{a}}$ & 17.71 & 23.00 & 111.00 \\
Lentulo & $68.84^{\mathrm{b}}$ & 29.85 & 22.00 & 136.00 \\
Rotary file & $99.77^{c}$ & 21.78 & 53.00 & 170.00 \\
\hline
\end{tabular}

Means sharing the same superscript letter are not significantly different $(p>0.05)$

Table 3. Mean density of calcium hydroxide in the canals with curvature of $24^{\circ}$ and $44^{\circ}$

\begin{tabular}{|c|c|c|c|c|}
\hline Canal curvature & Mean & SD & Minimum & Maximum \\
\hline $24^{\circ}$ & $83.65^{\mathrm{b}}$ & 25.81 & 26.00 & 143.00 \\
$44^{\circ}$ & $69.20^{\mathrm{a}}$ & 30.25 & 22.00 & 170.00 \\
\hline
\end{tabular}

Means sharing the same superscript letter are not significantly different $(p>0.05)$.

Table 4. Mean density of calcium hydroxide at different distances from the apex

\begin{tabular}{|l|c|c|c|c|}
\hline \multicolumn{1}{|c|}{ Distance } & Mean & SD & Minimum & Maximum \\
\hline $1 \mathrm{~mm}$ & $70.82^{\mathrm{a}}$ & 30.84 & 22.00 & 143.00 \\
$3 \mathrm{~mm}$ & $71.60^{\mathrm{a}}$ & 29.99 & 22.00 & 148.00 \\
$7 \mathrm{~mm}$ & $78.26^{\mathrm{ab}}$ & 26.92 & 22.00 & 157.00 \\
$11 \mathrm{~mm}$ & $85.02^{\mathrm{b}}$ & 26.15 & 31.00 & 170.00 \\
\hline
\end{tabular}

Means sharing the same superscript letter are not significantly different $(p>0.05)$.

\section{Discussion}

This study compared the efficacy of 3 methods of delivering calcium hydroxide into the canal, namely the manual technique, a Lentulo and a rotary file. The results showed that the density of calcium hydroxide delivered into the canals was affected by the technique of delivery and the canal curvature.

In this study, simulated root canals in transparent resin blocks were used to assess the effect of the canal curvature on the density of calcium hydroxide. Some studies have also considered the role of the canal curvature and standardized the samples in this respect. ${ }^{7,9-11}$ However, to the best of the authors' knowledge, no previous study has assessed the effect of the canal curvature on calcium hydroxide delivery into different parts of the canal. Thus, we evaluated canals with curvature of $24^{\circ}$ and $44^{\circ}$ and the density of calcium hydroxide was evaluated at different distances from the apex to assess the effect of the canal curvature on this variable. Some previous studies simulated canals with curvature of $44^{\circ}$ (sizes 40 and 50)..$^{9,10}$ It has been suggested to decrease the size of a master apical file to 20 or 25 in the preparation of severely curved or S-shaped canals to prevent procedural errors. ${ }^{12,13}$ Simcock and Hicks showed that in a canal prepared with a master apical file size 25 (as the minimum amount of canal preparation), only $45 \%$ of the optimal amount of calcium hydroxide is delivered, but in canals prepared with a master apical file size 40 , calcium hydroxide is more efficiently delivered. ${ }^{7}$ 
Staehle et al. recommended the canal preparation to size 50 in order to enhance the density of calcium hydroxide. ${ }^{14}$ Deveaux et al. suggested canal preparation to size 50 in straight canals or those with a slight curvature to enhance the density of calcium hydroxide. ${ }^{10}$ We considered size 30 canals in this study, since one of our objectives was to assess the quality of delivery of calcium hydroxide in severely curved canals with curvature of $44^{\circ}$.

It should be noted that a Lentulo may break in the canal'; 1 such case of a Lentulo fracture occurred in our study. A Lentulo fracture has a higher frequency in severely curved canals. In the case of a Lentulo fracture, removing the broken piece from the canal is difficult. Thus, the use of plastic syringes is often preferred to a Lentulo for the delivery of a medicament into the canal..$^{8-10,12}$

Several studies have shown that the technique of delivering calcium hydroxide into the canal affects its density in the root canal system. The current results showed a significant difference in the density of calcium hydroxide delivered into the canal with 3 different methods of a hand file, a Lentulo and a rotary file; this finding was in agreement with those of previous studies. . $^{6,8,9,11,12}$

The current findings regarding the lowest density of calcium hydroxide delivered into the canal using the manual technique (a hand file) were in accordance with the findings of previous studies. ${ }^{7,9,10}$ The density of calcium hydroxide delivered with a Lentulo was higher compared to a hand file; this finding also confirmed the results of previous studies., ${ }^{9,11}$ The current results also revealed that a rotary file was superior to a Lentulo in delivering calcium hydroxide into the canal. Simock and Hicks concluded that a Lentulo is not significantly different from a rotary file for the delivery of calcium hydroxide into minimally or optimally prepared canals. ${ }^{7}$ However, they evaluated extracted teeth in their study and excluded curved canals, since the curvature is considered an influential factor in this respect. They estimated the density of calcium hydroxide by weighing its amount delivered into the canal. Our study showed that a Lentulo and a rotary file showed a similar performance in the coronal areas of the canals with curvature of $24^{\circ}$ with regard to the density of calcium hydroxide.

The current findings showed that the density of calcium hydroxide delivered with a rotary file was the highest compared to the other 2 methods of delivery. Rotary instruments show a fast and uniform performance in the canal preparation. Moreover, rotary files can access the entire root canal length (especially in the apical region) due to the flexibility of NiTi files in curved canals. The NiTi rotary systems are more and more frequently used for the root canal preparation. They provide clean and smooth root canal walls and create a relatively round cross-sectional shape. ${ }^{12}$ They can be used safely in curved canals as well. ${ }^{15}$ Rotary files can extrude dentinal debris easily from the root canal when operating clockwise. ${ }^{16}$ They can also deliver calcium hydroxide and sealers into the canal when operating counterclockwise. ${ }^{11}$ Thus, rotary systems and a Lentulo can efficiently deliver calcium hydroxide with optimal density into the canals.

The current results regarding the density of calcium hydroxide delivered with 3 methods into the root canals with curvature of $24^{\circ}$ and $44^{\circ}$ revealed that the degree of curvature can affect the density of calcium hydroxide delivered into the canal using a hand file and a Lentulo. In the canals with curvature of $24^{\circ}$, the density of calcium hydroxide at $1 \mathrm{~mm}, 3 \mathrm{~mm}, 7 \mathrm{~mm}$, and $11 \mathrm{~mm}$ from the apex was higher. However, in the case of a rotary file, the curvature had no effect on the density of calcium hydroxide. The findings also indicated that in delivering calcium hydroxide by means of a hand file, a Lentulo and a rotary file into the canal, the highest density was noted at $11 \mathrm{~mm}$ from the apex.

The current results confirmed that the canal curvature affects the density of calcium hydroxide delivered into the canal in such a way that the calcium hydroxide density in more severely curved canals $\left(44^{\circ}\right)$ was significantly decreased compared to canals with less curvature $\left(24^{\circ}\right)$. This finding should be taken into account by clinicians. Future studies are warranted to assess the time required for delivering calcium hydroxide into the canal by rotary files and its substantivity. Also, the efficacy of different rotary files with variable cross-sectional designs for the calcium hydroxide delivery into the canals of extracted human teeth should be compared in further studies.

\section{Conclusions}

The current results revealed that the canal curvature affects the delivery of calcium hydroxide into the canal. A rotary file operating counterclockwise yielded the highest density of calcium hydroxide in more apical regions and in the canals with greater curvature compared to Lentulo and a hand file.

\section{ORCID iDs}

Roohollah Sharifi (1) https://orcid.org/0000-0001-7917-5409 Ehsan Bahrampour (1) https://orcid.org/0000-0001-7467-5770 Pourya Janfroozzade (1) https://orcid.org/0000-0000-0000-0001 Mohsen Safaei (1) https://orcid.org/0000-0003-3885-6640 Hamid Reza Mozaffari (1) https://orcid.org/0000-0001-9351-1499 Elham Soltanimehr (1) https://orcid.org/0000-0001-6207-5057 Hedaiat Moradpoor (1) https://orcid.org/0000-0002-9161-8038 Mohammad Moslem Imani (]) https://orcid.org/0000-0002-3982-5216

\section{References}

1. Gangwar A. Antimicrobial effectiveness of different preparations of calcium hydroxide. Indian J Dent Res. 2011;22(1):66-70.

2. Vianna ME, Gomes BP, Sena NT, Zaia AA, Ferraz CC, de Souza Filho FJ. In vitro evaluation of the susceptibility of endodontic pathogens to calcium hydroxide combined with different vehicles. Braz Dent J. 2005;16(3):175-180.

3. Siqueira JF Jr, Lopes HP. Mechanisms of antimicrobial activity of calcium hydroxide: A critical review. Int Endod J. 1999;32(5):361-369.

4. Singh RD, Khatter R, Bal RK, Bal CS. Intracanal medications versus placebo in reducing postoperative endodontic pain - a doubleblind randomized clinical trial. Braz Dent J. 2013;24(1):25-29. 
5. Murad C, Fariniuk LF, Fidel S, Fidel RA, Sassone LM. Bacterial leakage in root canals filled with calcium hydroxide paste associated with different vehicles. Braz Dent J. 2008;19(3):232-237.

6. Deonízio MD, Sydney GB, Batista A, Estrela C. Root canal filling with calcium hydroxide paste using Lentullo spiral at different speeds. Dental Press Endod. 2011;1(1):58-63.

7. Simcock RM, Hicks ML. Delivery of calcium hydroxide: Comparison of four filling techniques. J Endod. 2006;32(7):680-682.

8. Tan JM, Parolia A, Pau AK. Intracanal placement of calcium hydroxide: A comparison of specially designed paste carrier technique with other techniques. BMC Oral Health. 2013;13:52.

9. Sigurdsson A, Stancill R, Madison S. Intracanal placement of $\mathrm{Ca}(\mathrm{OH})_{2}$ : A comparison of techniques. J Endod. 1992;18(8):367-370.

10. Deveaux E, Dufour D, Boniface B. Five methods of calcium hydroxide intracanal placement: An in vitro evaluation. Oral Surg Oral Med Oral Pathol Oral Radiol Endod. 2000;89(3):349-355.

11. Torres CP, Apicella MJ, Yancich PP, Parker MH. Intracanal placement of calcium hydroxide: A comparison of techniques, revisited. $J$ Endod. 2004;30(4):225-227.

12. Bryant ST, Thompson SA, al-Omari MA, Dummer PM. Shaping ability of ProFile rotary nickel-titanium instruments with ISO sized tips in simulated root canals: Part 1. Int Endod J. 1998;31(4):275-281.

13. Loizides AL, Kakavetsos VD, Tzanetakis GN, Kontakiotis EG, Eliades G. A comparative study of the effects of two nickel-titanium preparation techniques on root canal geometry assessed by microcomputed tomography. J Endod. 2007;33(12):1455-1459.

14. Staehle $H$, Thomä C, Müller HP. Comparative in vitro investigation of different methods for temporary root canal filling with aqueous suspensions of calcium hydroxide. Endod Dent Traumatol. 1997;13(3):106-112.

15. Celik D, Taşdemir T, Er K. Comparative study of 6 rotary nickel-titanium systems and hand instrumentation for root canal preparation in severely curved root canals of extracted teeth. $J$ Endod. 2013;39(2):278-282.

16. De-Deus GA, Noguiera Leal Silva EJ, Moreira EJ, de Almeida Neves $A$ Belladonna FG, Tameirão M. Assessment of apically extruded debris produced by the self-adjusting file system.J Endod. 2014;40(4):526-529. 
